doi:10.4149/neo_2014_006

\title{
Prognostic implication of TIM-3 in clear cell renal cell carcinoma
}

\author{
J. YUAN*, B. JIANG, H. ZHAO, Q. HUANG \\ Department of Urology, Jiangyin Hospital, Medical School of Southeast University, Jiangyin, 214400, Jiangsu Province, China \\ ${ }^{*}$ Correspondence: dndxyuanj@yeah.net
}

Received March 6, 2013 / Accepted April 26, 2013

\begin{abstract}
Clear cell renal carcinoma (ccRCC) is the most common tumor of the kidney.in adults. The prognosis of ccRCC remains unsatisfactory. Recently, T cell immunoglobulin mucin-3 (TIM-3), a novel transmembrane protein, has been implicated in tumor biology. Its role in ccRCC remains unkonwn. The aim of this study was to investigate the roles of TIM-3 as a prognostic marker in patients with ccRCC.TIM-3 protein expression was determined by immunohistochemistry and Western blot from 137 ccRCC tumor samples and adjacent normal renal tissues. We performed also the cell proliferation assay using 3-(4,5dimethylthiazol-2yl)-2,5-diphenyl-2H tetrazolium bromide (MTT) and cell invasion assay. The effects of small interfering RNA (siRNA)-mediated knockdown of TIM-3 (TIM-3 siRNA) in two human ccRCC cell lines were evaluated. TIM-3 expression was higher in ccRCC tissue than in the adjacent normal renal tissue $(\mathrm{P}<0.001)$. High TIM-3 expression was an independent predictor of both cancer-specific survival and progression-free survival. TIM-3 protein was expressed in both ccRCC cell lines. Knockdown of TIM-3 suppressed the proliferation and invasion capacity of ccRCC cell lines.TIM-3 expression was associated with poor prognosis in ccRCC. Taken together, TIM-3 is a potential prognostic marker in ccRCC.
\end{abstract}

Key words: TIM-3, clear cell renal cell carcinoma, prognosis, marker

Renal cell carcinoma (RCC) has a global impact. Approximately 111,100 new cases and 43,000 deaths of the disease were seen among men in developed countries in 2008 alone [1]. Clear cell RCC (ccRCC) is the most common histological subtype of RCC, comprising nearly $75 \%$ of all kidney cancers [2]. Immunotherapeutic drugs such as interferon- $\alpha$ and interleukin-2 have been the primary treatment options, despite low response rates and significant toxicity in the past decades [3-5]. Despite the use of novel therapeutic approaches involving vascular endothelial growth factor (VEGFR), platelet derived growth factor, and PI3K [6], these drugs only have modest response rates. Thus, it is necessary to identify new molecular targets in ccRCC for the development of more effective therapeutic strategies.

$\mathrm{T}$ cell immunoglobulin mucin-3 (TIM-3), a membrane protein, plays a pivotal role in immune regulation [7]. Current studies have demonstrated a strong correlation between TIM-3 expression and tumor-associated immune suppression. TIM-3 can be upregulated by transforming growth factor $\beta$ (TGF- $\beta$ ) treatment and contributes to the survival of melanoma [8]. Targeting TIM-3 pathways may reverse $\mathrm{T}$ cell exhaustion and restore anti-tumor immunity [9]. In melanoma patients, up- regulation of TIM-3 is associated with tumor antigen-specific $\mathrm{CD}^{+} \mathrm{T}$ cell dysfunction [10]. In addition, TIM-3 suppresses activation of $\mathrm{CD}^{+} \mathrm{T}$ lymphocytes through the activation of the interleukin-6-STAT3 pathway and also facilitates the establishment of lymphoma immune tolerance [11]. However, the role of TIM-3 in ccRCC remains largely unknown.

The goal of this study was to examine the significance of TIM-3 in ccRCC. We detected the expression of TIM-3 protein in primary ccRCC tumors from a large population of patients. In vitro studies were also carried out to investigate the role of TIM-3 expression in ccRCC cell lines.

\section{Materials and methods}

Patients and tissue specimens. Specimens of ccRCC and paired normal renal tissues ( $n=137$ per group) were collected from patients in the Urology Department of our hospital between January 2006 and December 2011. All patients were newly diagnosed as ccRCC by histopathology, who did not receive any treatment previously. Normal renal tissues were surgically excised from the same patients and confirmed as normal by histology. Of the 137 ccRCC patients, 111 under- 
went radical nephrectomy and 26 patients underwent partial nephrectomy. All specimens were obtained immediately after surgical removal, snap-frozen in liquid nitrogen and stored at $-80^{\circ} \mathrm{C}$. Informed consent was obtained from all patients. Recurrence or metastasis of ccRCC and disease-related death were obtained from the review of medical records. Tumor stage and nuclear grading were classified according to the 2010 tumor, node and metastasis (TNM) stage system. This study was approved by the Institutional Review Board of Medical School of Southeast University.

Immunohistochemical and / western blot detection of TIM-3. Paraffin-embedded tissue sections were subjected to immunohistochemical analysis as described previously [12]. Anti-TIM-3 antibody (Abcam) was used in the present study. For semiquantitative evaluation, intensity of staining was designated as $0,1+, 2+, 3+$ and $4+$. These data were compared between various experimental groups. In addition, Western blot was used to prove the specificity of anti-Tim-3 antibody and confirm the expression of Tim-3.

Cell lines. Two human ccRCC cell lines (A498 and 769P) were purchased from the American Type Culture Collection

Table 1. Correlations of clinicopathologic features with Tim-3 expression

\begin{tabular}{|c|c|c|c|c|c|}
\hline & & Cases & $\begin{array}{r}\text { Tim-3 ex } \\
\quad(\mathrm{n}=\end{array}$ & $\begin{array}{l}\text { pression } \\
\text { 37) }\end{array}$ & D \\
\hline & & n (\%) & $\begin{array}{c}\text { Low } \\
(\mathrm{n}=109)\end{array}$ & $\begin{array}{l}\text { High } \\
(\mathrm{n}=28)\end{array}$ & P-value \\
\hline $\mathrm{T}$ & 1 & $87(63.5)$ & 70 & 17 & 0.427 \\
\hline & 2 & $23(16.8)$ & 20 & 3 & \\
\hline & 3 & $26(19.0)$ & 18 & 8 & \\
\hline & 4 & $1(0.7)$ & 1 & 0 & \\
\hline $\mathrm{N}$ & No & $134(97.8)$ & 107 & 27 & 0.499 \\
\hline & N1 & $3(2.2)$ & 2 & 1 & \\
\hline M & M0 & $124(90.5)$ & 100 & 24 & 0.303 \\
\hline & M1 & $13(9.5)$ & 9 & 4 & \\
\hline TNM stage & I & $86(62.8)$ & 69 & 17 & 0.581 \\
\hline & II & $18(13.1)$ & 16 & 2 & \\
\hline & III & 19(13.9) & 14 & 5 & \\
\hline & IV & $14(10.2)$ & 10 & 4 & \\
\hline Nuclear grade & 1 & $9(6.6)$ & 8 & 1 & 0.744 \\
\hline & 2 & $61(44.5)$ & 48 & 13 & \\
\hline & 3 & $49(35.8)$ & 40 & 9 & \\
\hline & 4 & $18(13.1)$ & 13 & 5 & \\
\hline $\operatorname{Age}(y r)$ & $<55$ & $73(53.3)$ & 58 & 15 & 1.000 \\
\hline & $\geq 55$ & $64(46.7)$ & 51 & 13 & \\
\hline Gender & Male & $107(78.1)$ & 81 & 26 & 0.04 \\
\hline & Female & $30(21.9)$ & 28 & 2 & \\
\hline Lung metastasis & Absent & $113(82.5)$ & 94 & 19 & 0.022 \\
\hline during follow-up & Present & $24(17.5)$ & 15 & 9 & \\
\hline Bone metastasis & Absent & $129(94.2)$ & 104 & 25 & 0.36 \\
\hline during follow-up & Present & $8(5.8)$ & 5 & 3 & \\
\hline
\end{tabular}

T: size or direct extent of the primary tumor; $\mathrm{T} 1, \mathrm{~T} 2, \mathrm{~T} 3$, T4: size and/or extension of the primary tumor; $\mathrm{N}$ : degree of spread to regional lymph nodes; N0: tumor cells absent from regional lymph nodes; N1: regional lymph node metastasis present; $\mathrm{M}$ : presence of distant metastasis;M0: no distant metastasis; M1: metastasis to distant organs. and maintained according to guidelines (http://www.atcc.org). Medium was supplemented with $10 \%$ fetal bovine serum and maintained at $37^{\circ} \mathrm{C}$ in a humidified atmosphere at $5 \% \mathrm{CO}_{2}$.

Quantitative RT-PCR (qRT-PCR). Total RNA was isolated using Trizol and reverse transcribed using SYBR ${ }^{\oplus}$ Quantitative PCR Kit (Invitrogen). Primers for TIM-3 (5'-TCCAAGGATGCTTACCACCAG-3', 5'-GCC AATGTGGATATTTGTGTTAGATT-3') were used and the transcript was normalized to GAPDH (forward, 5'-GACCCTTCATTGACCTC-3', reverse, GCAATG CCAGCCCCAG) transcript levels.

Western blot. Cell lysates were resolved using a $10 \%$ polyacrylamide gel in a sodium dodecyl sulfate buffer by electrophoresis. After being transferred onto nitrocellulose membrane, the blots were incubated with anti-TIM-3 antibody (Abcam). Binding of TIM-3 antibody was revealed by chemiluminescence after incubation with horseradish peroxidise-conjugated goat anti-mouse antibody (Bio-Rad Laboratories). $\beta$-Tubulin (Abcam) was used as the internal control.

Cell proliferation assay. To evaluate the effects of TIM-3 inhibition on the proliferation of ccRCC cell lines, 3-(4,5dimethylthiazol-2yl)-2,5-diphenyl-2H tetrazolium bromide (MTT) assay was carried out. TIM-3 siRNA or control siRNA (Santa Cruz) was chosen to selectively inhibit TIM-3 activity. Briefly, $1 \times 10^{5}$ cells of each group were plated per well in 24well plates. Both RCC cell lines were incubated with various concentrations of TIM-3 siRNA $(0,0.4,0.8,1,1.2$, and $1.5 \mu \mathrm{M})$. After a 48-hour incubation, the MTT substrate (Sigma, $5 \mathrm{mg}$ / $\mathrm{mL}$ in phosphate buffered saline) was added to each well, and the cells were incubated at $37^{\circ} \mathrm{C}$ for four hours. Following the elimination of the culture medium, the cells were dissolved in a $1 \mathrm{~mL}$ of dimethyl sulfoxide. The optical density was measured using a microplate reader at $490 \mathrm{~nm}$ wavelength. Each experiment was repeated three times.

Cell invasion assay. To evaluate the influence of TIM-3 inhibition on invasive capacity of ccRCC cell lines, we used a CHEMICON cell invasion assay kit (Millipore) according to the manufacturer's instructions. A498 and 769P cells $\left(1 \times 10^{5}\right)$ were seeded in the upper chamber in a $300 \mu \mathrm{L}$ of serum free media incubated with treatment of a $1.0 \mu \mathrm{M}$ of TIM-3 siRNA, and a $500 \mu \mathrm{L}$ of $10 \%$ FBS medium was placed in the lower chamber as a chemo-attractant. The cells were incubated for 48 hours at $37^{\circ} \mathrm{C}$ in a $5 \% \mathrm{CO}_{2}$ chamber. This was followed by the removal of the cells on the upper surface of the membrane using a cotton swab. The cells, infiltrating to the lower surface of the membrane, were fixed with methanol and stained for 20 minutes, and then the number was counted from 10 random microscopic fields at a $\times 100$ magnification.

Statistical analysis. SPSS 17.0 and GraphPad Prism 5.0 were used for data analyses. Prognosis was assessed using the Cox proportional hazards model. Associations between clinical/pathological parameters and protein expression were assessed using student t-test. Kaplan-Meier survival curves and Mantel-Cox log-rank test were used. 

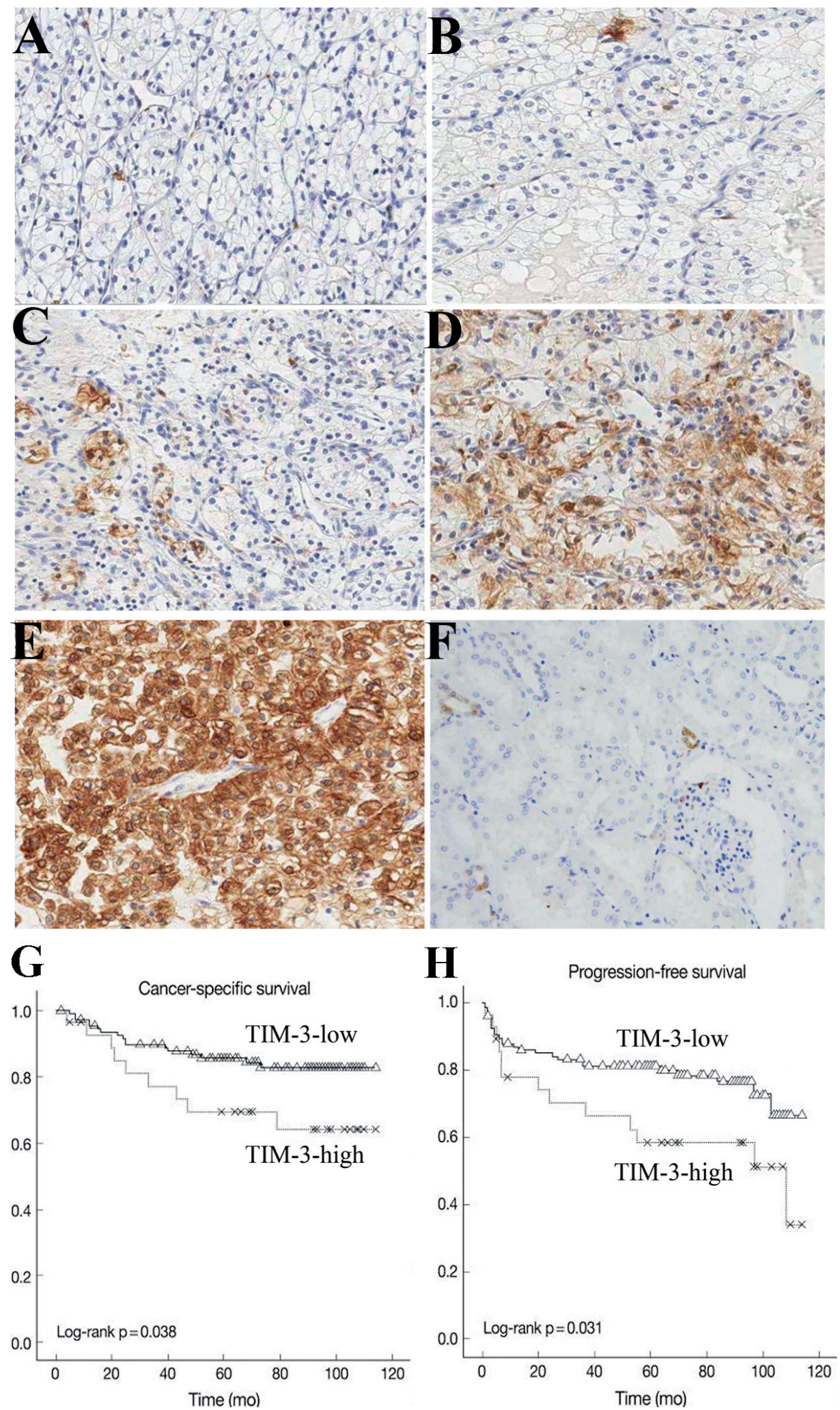

Figure 1. Immunohistochemical findings and survival analysis in clear cell renal cell carcinoma (ccRCC). Immunohistochemical findings of $\mathrm{T}$ cell immunoglobulin mucin-3 (TIM-3) showing 0 (A), 1+ (B), 2+ (C), 3+ (D), and 4+ (E). Adjacent normal renal tissue (F) shows only focal immunoreactivity in a few renal tubules. Kaplan-Meier curves of cancer-specific $(G)$ and progression-free $(H)$ survival in 137 patients with ccRCC depending on the $T$ cell TIM-3 expression. 


\section{$12 \underset{2}{2}-456 \quad$ TIM-3}

\section{$\beta$-Tubulin}

Figure 2. Western blot analysis of T cell immunoglobulin mucin-3 (TIM$3,35 \mathrm{kD}$ ) in clear cell renal cell carcinoma (ccRCC) compared with adjacent normal renal tissue. ccRCC: Lane 1-3; normal tissue:4-6. The internal control $(\beta$-Tubulin, $55 \mathrm{kD})$ were used.

\section{Results}

Clinicopathological features. The clinicopathological characteristics of patients with ccRCC are summarized in Table 1. The 137 patients included 107 men and 30 women, with mean age 57 years (range 29 to 81 years). During the follow-up period, there were 24 cases $(17.5 \%)$ of pulmonary metastasis and eight cases $(5.8 \%)$ of bone metastasis. The mean follow-up period was 70 months (range 3 to 115 months).

Correlations between TIM-3 and clinicopathological features. An analysis of TIM-3 expression was performed in 137 ccRCC tumor samples. The staining intensity was scored from 0 to $4+$. Results included five cases of 0,79 cases of $1+$, 25 cases of $2+, 14$ cases of $3+$, and 14 cases of $4+$ (Fig. 1). To evaluate the statistical significance, the cases were redistributed into two groups according to the degree of their expression: the TIM-3-low group $(0,1+$, and $2+; \mathrm{n}=109,79.6 \%)$ and the TIM-3-high group ( $3+$ and $4+; n=28,20.4 \%)$. The correlations between TIM-3 immunoreactivity and clinicopathological variables are summarized in Table 1. The TIM-3 expression was statistically higher in ccRCC and also correlated with the pulmonary metastasis based on follow-up. TIM-3 was only focally expressed in the renal tubular epithelial cells forming the non-neoplastic renal tissue (Fig. 1F). In addition, Western blot proved the specificity of Tim-3 antibody and confirmed the protein expression of Tim-3 (Fig. 2).

TIM-3 expression and prognosis. The cancer-specific and progression-free survival were significantly shorter in the TIM-3-high group as compared with the TIM-3-low group ( $\mathrm{p}=0.038$ and $\mathrm{p}=0.031$, respectively) (Fig. $1 \mathrm{G}, \mathrm{H})$. On univariate analysis, the TIM-3 expression had a significant association with cancer-specific or progression-free survival, TNM stage, and nuclear grade (all $\mathrm{p}<0.01$ ). On multivariate analysis, TIM-3 expression was an independent predictor of both cancer-specific [risk ratio $=2.08 ; 95 \%$ confidence interval $(\mathrm{CI}) 1.07-4.16$; $\mathrm{P}=0.007$ ] and progression-free survival [risk ratio $=2.23 ; 95 \%$ confidence interval (CI) 1.42-4.57; $\mathrm{P}<0.001$ ].

Effect of TIM-3 siRNA on tumor cell proliferation and invasion. Western blot analysis showed positive TIM-3 expression on both A498 and 769P cell lines (Fig. 3). MTT assay was performed to assess the effects of TIM- 3 siRNA on the viability

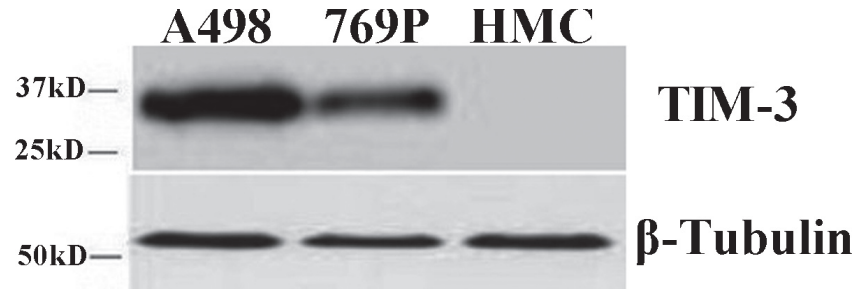

Figure 3. Western blot analysis of $\mathrm{T}$ cell immunoglobulin mucin-3 (TIM3,35kD) from A498 and 769P cell lines. Both cell lines expressed TIM-3 protein. A normal cell line human mesangial cell (HMC, ATCC) and an internal control ( $\beta$-Tubulin, $55 \mathrm{kD})$ were used.

and proliferation of the cell lines. The effects of TIM-3 siRNA were confirmed by qRT-PCR and Western blot (Fig. 4 A, B).

The TIM-3 siRNA-treated group revealed a dose-dependent suppression of cell proliferation (Fig. 4 C, D). And results showed that TIM-3 siRNA inhibited the invasion capacity of both A498 and 769P ccRCC cell lines (Fig. 4 E, F). These results demonstrated that TIM-3 siRNA down-regulated both the proliferation and invasion capacity of ccRCC cell lines.

\section{Discussion}

To date, there have been limited number of reports on the importance of the TIM-3 in ccRCC. A recent study suggests that TIM-3 polymorphisms are associated with RCC [13]. Here, we demonstrated positive TIM-3 expression in tumor tissues from patients with ccRCC, whereas normal lung tissues lacked any positive expression of TIM-3. In addition, we found a statistically significant correlation between TIM-3 protein expression in tumor tissues and clinicopathologic parameters. More important was that we found that the survival rate of patients with high TIM-3 expression tumors was significantly lower than that of those patients with low TIM-3 expression. The univariate and multivariate analyses revealed that TIM-3 status in tumor tissues was an independent prognostic factor of ccRCC.

Wiener et al [8] found that Tim-3 was expressed not only in mast cells around melanomas, but also in tumor cells in tissue sections and human melanoma cell lines WM35 and HT168-M1, in line with our study. Studies have also identified Tim-3 expression on leukemia stem cells in patients with acute myeloid leukemia [14-15].

The link between Tim-3 expression and tumor cell itself has not yet been well defined. To further investigate the role of the TIM-3 pathway in ccRCC, in vitro studies were carried out in our study. Positive TIM-3 expression was identified in all two ccRCC cell lines. One striking finding was that exposure to TIM-3 siRNA resulted in significant inhibition of cell proliferation and invasion. How is Tim-3 involved in tumor biology? In vitro, Tim-3 can activate the interleukin-6 (IL-6)-STAT3 pathway. In a lymphoma mouse model, Tim-3 promotes the onset, growth, and dissemina- 

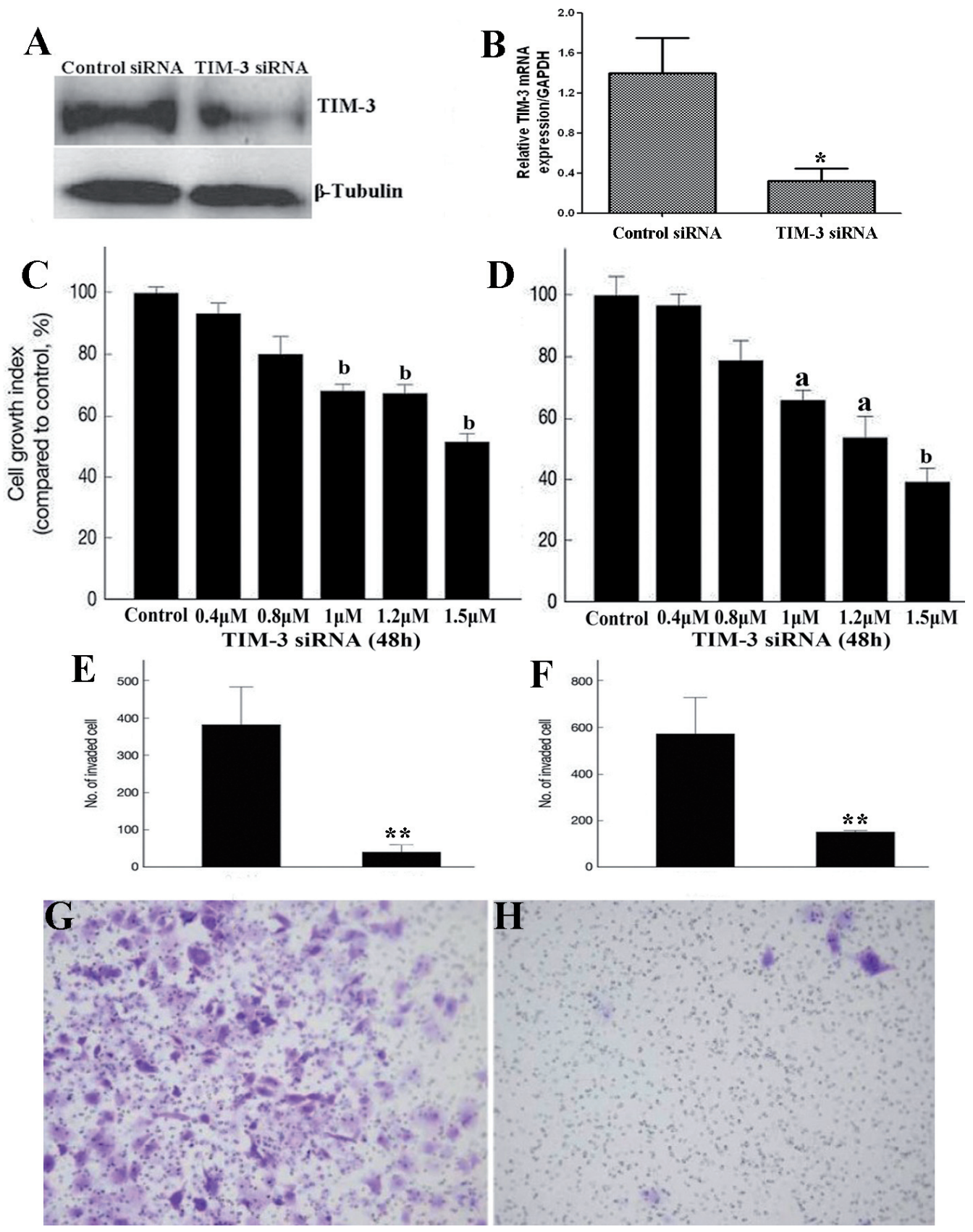

Figure 4. Inhibition of cell proliferation and invasion by T cell immunoglobulin mucin-3 (TIM-3) siRNA treatment. Western blot (A) and real time PCR (B) proved the downregulation of Tim-3 expression at mRNA and protein levels by $1.0 \mu \mathrm{M}$ siRNA for $48 \mathrm{hr}\left({ }^{*} \mathrm{p}<0.01\right)$. MTT assay shows growth inhibition of A498 (C) and 769P (D) cell lines after treatment with various concentrations of TIM-3 siRNA for 48 hr. Data presents as the percentage of control and shows mean \pm standard deviation from three independent experiments $\left({ }^{\mathrm{a}} \mathrm{p}<0.05,{ }^{\mathrm{b}} \mathrm{p}<0.01\right)$. Histograms show the reduced invasive capacity of A498 (E) and 769P (F) cell lines after treatment with a $1.0 \mu \mathrm{M}$ TIM-3 siRNA for $48 \mathrm{hr}$. Representative photographs reveal reduced invaded A498 cells by a $1.0 \mu \mathrm{M}$ of TIM-3 siRNA treatment $(\mathrm{H})$ for $48 \mathrm{~h}$ compared to control A498 cells $(\mathrm{G})$. Data presents as the mean invaded cell number Mean \pm standard deviation from three independent experiments $(* \mathrm{p}<0.01)$.

tion of lymphoma by inhibiting activation of $\mathrm{CD} 4^{+} \mathrm{T}$ cells and Th1 polarization [11]. According to published data [1617], IL-6-STAT3 pathway plays an important role in tumor growth. IL-6-STAT3 signaling is involved in tumor growth and metastasis of human hepatocellular carcinoma [16]. In addition, DNA damage induces the IL-6-STAT3 signaling pathway, which has growth-promoting functions in human tumors [17]. Based on these previous findings and our results, 
we hypothesize that Tim-3 might facilitate tumor metastasis through the IL-6-STAT3 pathway.

Taken together, our work confirms that TIM-3 protein expression is associated with poor survival in ccRCC. Based on in vitro activity of TIM-3 siRNA in ccRCC cell lines, TIM-3 might be a good target for this disease. However, several limitations of this investigation should be acknowledged. This includes the modest number of TIM-3-high patients and the extent of clinical/pathologic variables included in the analysis. For the in vitro studies, a more extensive panel of RCC cell lines, including papillary and sarcomatoid RCCs, could strengthen the broad application of TIM-3-targeted therapy. Thus, further evaluation of TIM-3 in both clear cell and non-clear cell RCCs and in a larger scale of ccRCC samples is warranted.

\section{References}

[1] JEMAL A, BRAY F, CENTER MM, FERLAY J, WARD E, et al. Global cancer statistics. CA Cancer J Clin 2011; 61: 69-90. http://dx.doi.org/10.3322/caac.20107

[2] COHEN HT, MCGOVERN FJ. Renal-cell carcinoma. N Engl J Med 2005; 353: 2477-2490. http://dx.doi.org/10.1056/ NEJMra043172

[3] FLANIGAN RC, SALMON SE, BLUMENSTEIN BA, BEARMAN SI, ROY V, et al. Nephrectomy followed by interferon alfa-2b compared with interferon alfa- $2 \mathrm{~b}$ alone for metastatic renal-cell cancer. N Engl J Med 2001; 345: 1655-1659. http:// dx.doi.org/10.1056/NEJMoa003013

[4] MCDERMOTT DF, REGAN MM, CLARK JI, FLAHERTY LE, WEISS GR, et al. Randomized phase III trial of highdose interleukin-2 versus subcutaneous interleukin-2 and interferon in patients with metastatic renal cell carcinoma. J Clin Oncol 2005; 23: 133-141. http://dx.doi.org/10.1200/ LCO.2005.03.206

[5] MICKISCH GH, GARIN A, VAN POPPEL H, DE PRIJCK L, SYLVESTER R, et al. Radical nephrectomy plus interferonalfa-based immunotherapy compared with interferon alfa alone in metastatic renalcell carcinoma: a randomised trial. Lancet 2001; 358: 966-970. http://dx.doi.org/10.1016/S01406736(01)06103-7

[6] SUN M, LUGHEZZANI G, PERROTTE P, KARAKIEWICZ PI. Treatment of metastatic renal cell carcinoma. Nat Rev Urol 2010; 7: 327-338. http://dx.doi.org/10.1038/nrurol.2010.57

[7] ZHUANG X, ZHANG X, XIA X, ZHANG C, LIANG X, et al. Ectopic expression of TIM-3 in lung cancers: a potential independent prognostic factor for patients with NSCLC. Am J Clin Pathol 2012; 137: 978- 985. http://dx.doi.org/10.1309/ AJCP9Q6OVLVSHTMY
[8] WIENER Z, KOHALMI B, POCZA P, JEAGER J, TOLGYESI G, et al. TIM-3 is expressed in melanoma cells and is upregulated in TGF-beta stimulated mast cells. J Invest Dermatol 2007; 127: 906-914. http://dx.doi.org/10.1038/ sj.jid. 5700616

[9] SAKUISHI K, APETOH L, SULLIVAN JM, BLAZAR BR, KUCHROO VK, et al. Targeting TIM-3 and PD-1 pathways to reverse $\mathrm{T}$ cell exhaustion and restore anti-tumor immunity. J Exp Med 2010; 207: 2187-2194. http://dx.doi.org/10.1084/ jem.20100643

[10] FOURCADE J, SUN Z, BENALLAOUA M, GUILLAUME P, LUESCHER IF, et al. Upregulation of Tim-3 and PD-1 expression is associated with tumor antigen-specific CD8+ T cell dysfunction in melanoma patients. J Exp Med 2010; 207: 2175-2186. http://dx.doi.org/10.1084/jem.20100637

[11] HUANG X, BAI X, CAO Y, WU J, HUANG M, et al. Lymphoma endothelium preferentially expresses TIM-3 and facilitates the progression of lymphoma by mediating immune evasion. J Exp Med 2010; 207: 505-520. http://dx.doi. org/10.1084/jem.20090397

[12] GENG H, ZHANG GM, LI D, ZHANG H, YUAN Y, et al. Soluble form of $\mathrm{T}$ cell Ig mucin 3 is an inhibitory molecule in T cell-mediated immune response. J Immunol 2006; 176: 1411-1420.

[13] CAI C, WANG L, WU Z, LI M, CHEN W, et al. T-cell immunoglobulin- and mucin- domain-containing molecule 3 gene polymorphisms and renal cell carcinoma. DNA Cell Biol 2012; 31: 1285-1289. http://dx.doi.org/10.1089/dna.2012.1625

[14] JAN M, CHAO MP, CHA AC, ALIZADEH AA, GENTLES AJ, et al. Prospective separation of normal and leukemic stem cells based on differential expression of Tim-3, a human acute myeloid leukemia stem cell marker. Proc Natl Acad Sci 2011; 108: 5009-5014. http://dx.doi.org/10.1073/ pnas. 1100551108

[15] KIKUSHIGE Y, SHIMA T, TAKAYANAGI S, URATA S, MIYAMOTO T, et al. Tim-3 is a promising target to selectively kill acute myeloid leukemia stem cells. Cell Stem Cell 2010; 7: 708-717. http://dx.doi.org/10.1016/j.stem.2010.11.014

[16] YANG X, LIANG L, ZHANG XF, JIA HL, QIN Y, et al. MicroRNA-26a suppresses tumor growth and metastasis of human hepatocellular carcinoma by targeting IL-6-Stat3 pathway. Hepatology 2013 (in press) doi: 10.1002/hep.26305. http:// dx.doi.org/10.1002/hep.26305

[17] YUN UJ, PARK SE, JO YS, KIM J, SHIN DY. DNA damage induces the IL-6/STAT3 signaling pathway, which has anti-senescence and growth-promoting functions in human tumors. Cancer Lett 2012; 323: 155-160. http://dx.doi.org/10.1016/ j.canlet.2012.04.003 